\title{
Accumulation Mechanism of Marine Shale Gas Reservoir in Anticlines: A Case Study of the Southern Sichuan Basin and Xiuwu Basin in the Yangtze Region
}

\author{
Kun Zhang, ${ }^{1,2,3,4}$ Yan Song $\mathbb{D}^{1,2,4}$ Shu Jiang $\mathbb{D}^{, 5,6,7}$ Zhenxue Jiang $\mathbb{D}^{1,2}$ Chengzao Jia, ${ }^{4}$ \\ Yizhou Huang, ${ }^{1,2}$ Ming Wen, ${ }^{1,2}$ Weiwei Liu, ${ }^{8}$ Pengfei Wang, ${ }^{9}$ Xin Li, ${ }^{1,2}$ Tianlin Liu, ${ }^{1,2}$ \\ Xuelian Xie, ${ }^{10}$ Chang'an Shan, ${ }^{11}$ Xiaoxue Liu, ${ }^{1,2}$ and Xin Wang ${ }^{1,2}$ \\ ${ }^{1}$ State Key Laboratory of Petroleum Resources and Prospecting, China University of Petroleum, Beijing 102249, China \\ ${ }^{2}$ Unconventional Natural Gas Institute, China University of Petroleum, Beijing 102249, China \\ ${ }^{3}$ Unconventional Petroleum Collaborative Innovation Center, China University of Petroleum, Beijing 102249, China \\ ${ }^{4}$ Research Institute of Petroleum Exploration and Development, Beijing 100083, China \\ ${ }^{5}$ Key Laboratory of Tectonics and Petroleum Resources of Ministry of Education, Faculty of Earth Resources, China University \\ of Geosciences, Wuhan 430074, China \\ ${ }^{6}$ Research Institute of Unconventional Oil \& Gas and Renewable Energy, China University of Petroleum (East China), \\ Qingdao 266580, China \\ ${ }^{7}$ Key Laboratory of Strategy Evaluation for Shale Gas, Ministry of Land and Resources, Beijing, China \\ ${ }^{8}$ Jiangxi Provincial Natural Gas Company Ltd., Nanchang 330000, China \\ ${ }^{9}$ Geoscience Documentation Center, China Geological Survey, Beijing 100083, China \\ ${ }^{10}$ Guangzhou Marine Geological Survey, Guangzhou 510075, China \\ ${ }^{11}$ School of Earth Sciences and Engineering, Xi'an Shiyou University, Xi'an 710065, China
}

Correspondence should be addressed to Yan Song; sya@petrochina.com.cn, Shu Jiang; jiangsu@cug.edu.cn, and Zhenxue Jiang; zhenxuejiangedu@126.com

Received 15 August 2018; Accepted 29 October 2018; Published 7 March 2019

Academic Editor: Paola Cianfarra

Copyright (c) 2019 Kun Zhang et al. This is an open access article distributed under the Creative Commons Attribution License, which permits unrestricted use, distribution, and reproduction in any medium, provided the original work is properly cited.

\footnotetext{
The study of tectonics is one of the important aspects of shale gas preservation. It is vital for understanding how to determine the enrichment regularity of marine shale gas in anticlines. This paper focuses on typical shale blocks in the southern Sichuan Basin and shale in the Upper Ordovician and the Lower Silurian. In this study, triaxial unloading tests, permeability tests perpendicular and parallel to the stratification plane, FIB-HIM tests, and inclusion analyses are carried out with real drilling data. The enrichment regularity of marine shale gas in anticlines is studied by considering 2 aspects: the angle of the limbs and the burial depth. For anticlines with adjacent synclines, the migration regularity of shale gas is considered by 3 aspects: the dynamics, channels, and processes of migration. This study reveals that a limb angle greater than $120^{\circ}$ reflects relatively good conditions for shale gas preservation, while limb angles lesser than $70^{\circ}$ indicate relatively poor conditions. This study also suggests that during the process of uplift, large-scale concentrated fractures will form at a certain depth range and horizontal stress field, resulting in the large loss of shale gas. The regression equation of the fractured depth $(H)$ and the horizontal stress $(S)$ is presented as $H=$ $15.404 S-754.41$ (with a correlation coefficient $R^{2}=0.6834$ ). The stratification plane and the organic pores form the migration channel of natural gas that is horizontal to the stratification plane in shale. Under the condition of both anticlines and contiguous synclines, shale gas escapes through fractures resulting from extrusion along the anticline and the uplift effect. In addition, driven by differences in the formation pressure coefficients, shale gas is capable of migrating in a short-distance stair-type style from synclines to the adjacent anticlines. Thus, if the drilling costs allow, the well locations should be placed in the more deeply buried synclines.
} 


\section{Introduction}

In recent years, due to the transformation of geological thinking and the progress of hydraulic fracturing technology, shale gas has become a popular topic in oil and gas exploration and development at home and abroad [1-5]. In 2010, Wei-201 Well was drilled in the Weiyuan structure, China, and the industrial breakthrough of shale gas resources in China was realized. Large-scale development has been achieved successfully in Chinese shale gas fields, such as Weiyuan, Changning, Fushun-Yongchuan, and Jiaoshiba in 2017 [6, 7]. Although progress has been made in shale gas exploration in China, there are large differences among the shale gas contents in different blocks and there have also been many failures alongside the successes in shale gas exploration. There remains a need for petroleum geologists to further study the shale gas enrichment mechanism [8-12]. The mainland of China is made up of a series of relatively small paleo-plates. Compared to that in North America, the Paleozoic marine shale in southern China has undergone a complex, multistage tectonic evolution, and thermal evolution after deposition. Although its material conditions are similar, such as the TOC content and mineral composition, there are still differences in the gas-bearing properties in different blocks and layers under different preservation conditions. Therefore, it is vital to quickly solve the problem of how to precisely select favorable areas [13-17].

Previous work has been done on the preservation conditions of shale gas. Tang et al. divide the southeast part of the Sichuan Basin into seven tectonic deformation zones based on structural research and systematically reveal geologic factors such as fracture scale, fracture density, lithology and thickness of the roof and floor, burial depth of the target layers, structure style, and fracture spacing index to establish the evaluation index and standard for the effective preservation area of shale gas and the comprehensive evaluation system of preservation conditions for shale gas [18]. Wang et al. use the Niutitang Formation in the Cen'gong block, Guizhou, as an example [19]. Through the detailed interpretation of seismic data and structural evolution analysis, the shale gas preservation conditions are studied in combination with the material basis, the roof and floor, the regional caprock, the natural gas component, the formation water conditions, and the formation pressure. In addition, after studying the Lower Cambrian and the Upper Ordovician-Lower Silurian shale in the Sichuan Basin and its periphery, Wei et al. demonstrated that the roof and floor conditions and the self-seal ability of shale are the key for shale gas retention in the early stages [20]. Additionally, the intensity and duration of tectonic transformation in the late stage have an obvious adjustment effect on the gas abundance of shale gas reservoirs. Furthermore, there is a distinguishable influence of the preservation conditions on gas content, porosity, water saturation, resistivity, and gas composition of shale gas. The gas content, porosity, and resistivity are relatively lower, and the water saturation and $\mathrm{N}_{2}$ content are relatively higher if the conditions are poor. These factors could be used as indirect indicators to evaluate the preservation conditions of shale gas.
The tectonic setting is an important aspect of the preservation conditions of shale gas [21]. Under the influence of continuous extrusion in the southeast direction, the steeply dipping anticlines and the adjacent wide synclines are usually developed $[6,7]$. In this paper, the geological factors and their mechanism of shale gas accumulation in anticlines were studied by considering 2 aspects: the angle of limbs and the burial depth, and the enrichment regulation is analyzed under conditions when anticlines and their adjacent synclines both exist. Thus, a shale gas enrichment model in anticlines is proposed.

\section{Geological Settings}

2.1. Tectonic Characteristics. The study area in the paper is the Yangtze area (Figure 1). It has been shown previously that the Yangtze and Cathaysian plates were separated by an oceanic basin [22-24]. The Yangtze plate is a cratonic basin. The Yangtze and Cathaysian plates in the Early Cambrian were in the state of stretching and large-scale transgression, and a set of organic-rich shale was deposited almost throughout the Yangtze plate. Then, the water body gradually became shallow and the lithology changed from fine-grained shale and silty shale into siltstone and sandstone. The Ordovician was influenced by the extrusion collision of the Cathaysian plate. The water body continued to shallow, from the clastic sedimentary system to the carbonate sedimentary system. In the Late Ordovician-Early Silurian, transgression occurred, leading to a change into the clastic sedimentary system and to the deposition of a set of organic-rich shale in the deep-water shelf. In the Cambrian to the Silurian, the oceanic basin between the two plates gradually subducted and collided towards the Yangtze plate, and by the end of the Late Silurian, the two plates were formally joined together to become a unified Southern China plate.

\subsection{Sedimentary and Stratum Characteristics}

2.2.1. The Lower Cambrian. Southern China is mainly composed of the South China plate, which consists of the Yangtze plate and the Cathaysian plate. Marine shale is mainly distributed in the Yangtze plate $[13,15,25,26]$. The Lower Cambrian is a stratum widely deposited on the Yangtze plate. Due to its wide area, it is name depends on the location. The Lower Cambrian is named the Qiongzhusi Formation in the Sichuan Basin in the Upper Yangtze region, is the Niutitang Formation outside the Sichuan Basin, and is the Wangyinpu Formation in the Lower Yangtze region. It comprises black or deep-gray organic-rich siliceous shale that was deposited in the Early Cambrian and is one of the exploration targets of shale gas in Southern China.

This paper illustrates the stratigraphic characteristics of the Lower Cambrian with the example of Jiangye-1 Well in the Xiuwu Basin, Lower Yangtze. As shown in Figure 2, the Lower Cambrian Wangyinpu Formation consists of a set of black siliceous shales, the underlying strata are the Upper Sinian Piyuancun Formation with gray siliceous dolomite, and the overlying strata are the Lower Cambrian Guanyintang Formation composed of a set of dark-gray siliceous 


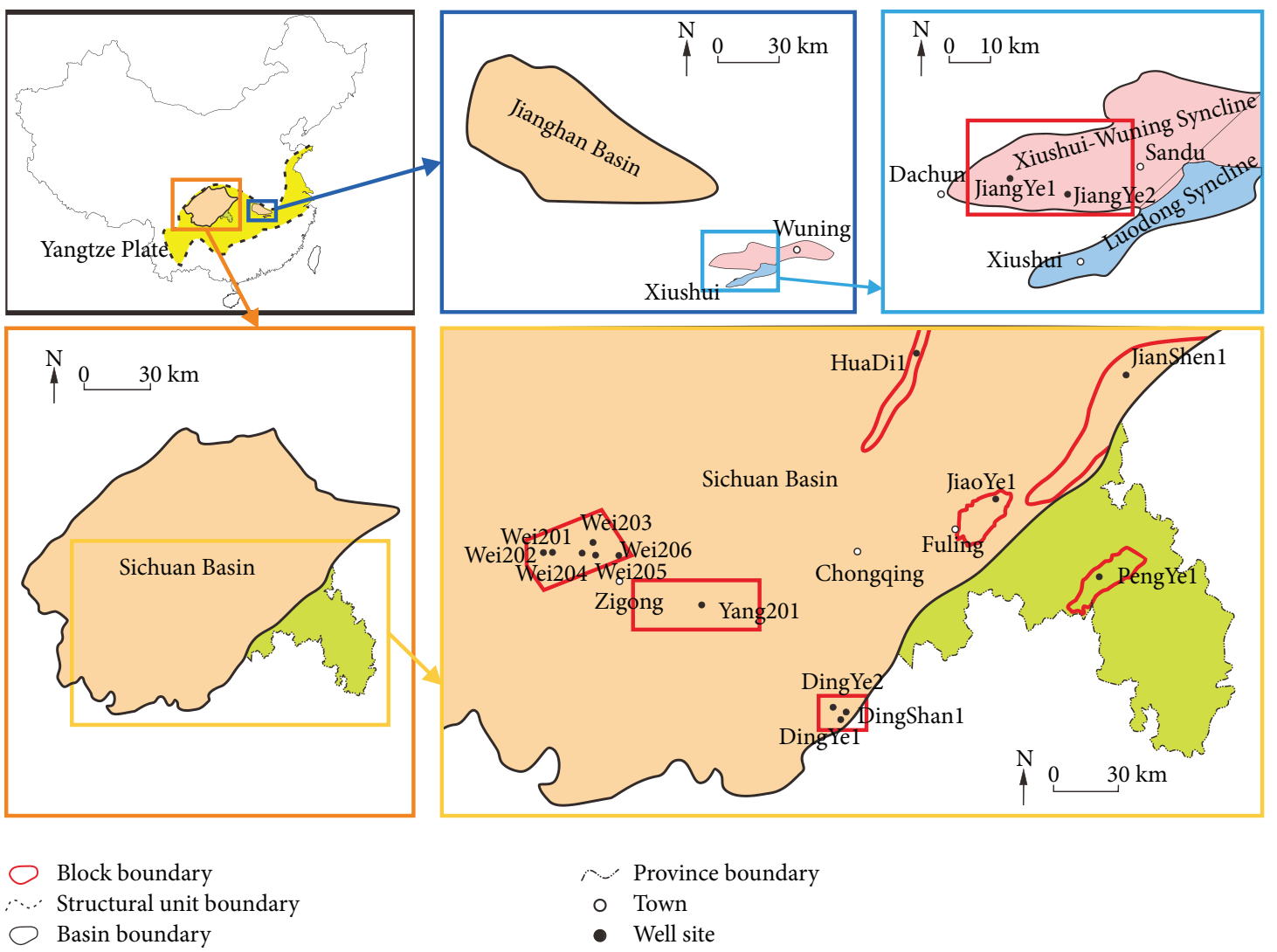

Figure 1: Location maps of the blocks, basins, and wells in this study, which include the Jiaoshiba, Pengshui, Shizhu, Huaying Mountain, Fushun-Yongchuan, and Weiyuan blocks; the Xiuwu basin; and the wells sampled therein.

shale. And the Lower Cambrian Wangyinpu Formation is the main target area of shale gas exploration.

According to previous studies [27, 28], in the Early Cambrian, there were deposits on the ancient land, the shallow-water shelf, the deep-water shelf (intrashelf low), the continental slope, and the ocean basin in the Yangtze plate from the northwest to the southeast.

2.2.2. The Upper Ordovician-Lower Silurian. The Upper Ordovician-Lower Silurian is another current exploration target in South China. Its name varies from place to place. In the Upper Yangtze region, the Late Ordovician stratum is the Wufeng Formation and the Early Silurian deposit is called the Longmaxi Formation. In the Lower Yangtze region, the Late Ordovician is named the Xinkailing Formation and the Early Silurian deposit is named the Lishuwo Formation. In this study, the research subject in the Upper Yangtze is the Wufeng Formation and the no. 1 section of Longmaxi Formation, and in the Lower Yangtze, it is the Xinkailing Formation and the no. 1 section of Lishuwo Formation. The lithology is divided into two parts in the Upper Ordovician and the Lower Silurian.

This paper illustrates the stratigraphic characteristics of the Upper Ordovician-Lower Silurian by taking Jiaoye-1 Well in the Sichuan Basin, Upper Yangtze Region, as an example. As shown in Figure 3, the Upper Ordovician Wufeng Formation no. 1 section of the Lower Silurian
Longmaxi Formation is composed of black siliceous shale, the underlying layer consists of the Upper Ordovician Linxiang greenish-grey warty limestone, and the overlying layer is the no. 2 section of the Lower Silurian Longmaxi Formation composed of grey silty shale. The Upper Ordovician Wufeng Formation no. 1 section of the Lower Silurian Longmaxi Formation is mainly the target for shale gas exploration.

Based on previous studies $[6,29,30]$, the Yangtze and Cathaysian plates converged in the Late Ordovician and the Early Silurian. The organic-rich shale formed in the area of the deep-water shelf of the Yangtze plate.

\section{Experiment Section}

3.1. Triaxial Unloading Test. The stress-strain process of unloading confining pressure under constant axial compression can be achieved by triaxial unloading testing, which is similar to the stratum loading process during uplift. The tests in this study used 16 samples from the Lower Silurian Longmaxi Formation shale in the Pengshui, Dingshan, and Shizhu blocks of the southeastern margin of the Sichuan Basin, as shown in Table 1. During the test, the axial pressure and confining pressure of the samples in the triaxial cylinder are increased in proper order, to prevent the samples from breaking during the pressurizing process. When the axial stress reaches the predetermined 


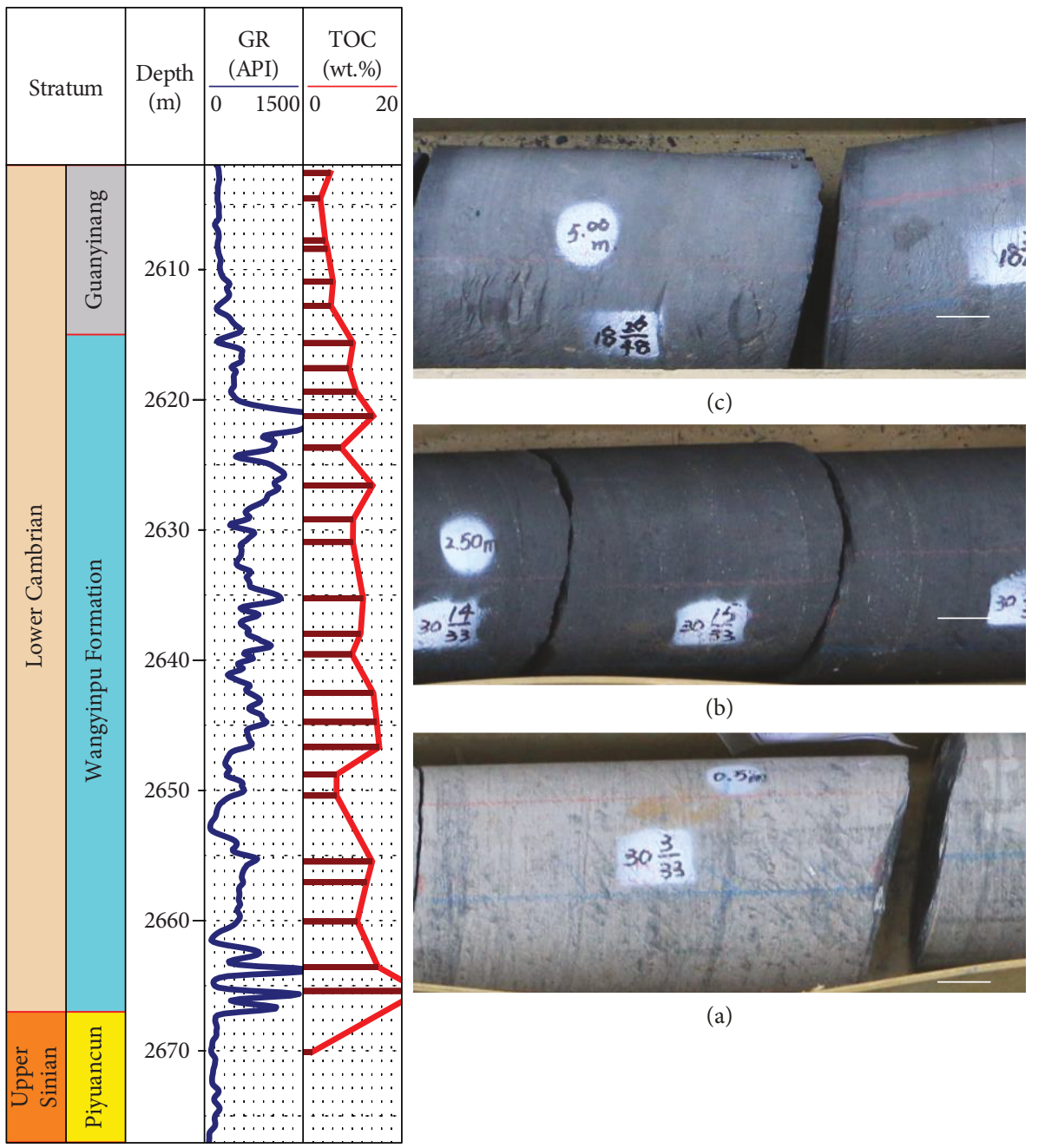

Figure 2: Stratigraphic column and core photos of the Upper Sinian Piyuancun Formation, the Lower Cambrian Wangyinpu Formation, and Guanyintang Formation in Jiangye-1 Well. (a) The Upper Sinian Piyuancun grey siliceous dolomite, 2673 m; (b) the Lower Cambrian Wangyinpu black siliceous shale, $2628 \mathrm{~m}$; (c) the Lower Cambrian Guanyintang dark-gray siliceous shale, $2607 \mathrm{~m}$. See Figure 1 for the well locations.

value (less than the triaxial compressive strength, but far greater than the uniaxial compressive strength of the rock sample), the axial stress is kept constant and the rock sample is gradually destroyed by only the confining pressure and the unloading rate is set as $0.1 \mathrm{MPa} / \mathrm{s}$. Some of the test data have been compared to the findings of $\mathrm{Li}$ et al. [31] and Guo et al. [32].

3.2. Permeability Tests Parallel and Perpendicular to the Stratification Plane. Ten samples were taken from the shale of the Lower Cambrian Wangyinpu Formation in the Lower Yangtze region, among which there are two samples from Jiangye-1 Well and eight samples from Jiangye-2 Well, as Table 1 shows in detail. The permeability tests parallel and perpendicular to the stratification plane are carried out by the overpressure permeability tester Poro PDP-200. The permeability test pressure was 1000 psi and the confining pressure was $1500 \mathrm{psi}$. In addition, the parallel and perpendicular permeability data are collected from $\mathrm{He}$ et al. [33].
The samples, 12 in total, were taken from Pengye-1 Well in the Pengshui block in the southeastern Sichuan Basin. The sample numbers are presented in Table 2.

3.3. FIB-HIM Experiment. Focused ion beam-Helium ion microscopy (FIB-HIM) is a three-beam system which combines the imaging function of high-resolution helium ion microscopy (HIM) and the cutting function of focused ion beam (FIB) and neon ion beam.

In this paper, the imaging of micropores was conducted by the NanoFab ORION microscope made by Carl Zeiss, Jena, Germany. It has higher resolution than field emission scanning electron microscopy (FE-SEM). With imaging resolution of $0.5 \mathrm{~nm}$, the NanoFab ORION can generate new insights with images that have 5 to 10 times greater depth of field when compared to images acquired with FE-SEM. Therefore, for tight rocks such as shale, in which pores with sizes lesser than $10 \mathrm{~nm}$ are absolutely predominant in number, the micropores that failed to be distinguished in the 

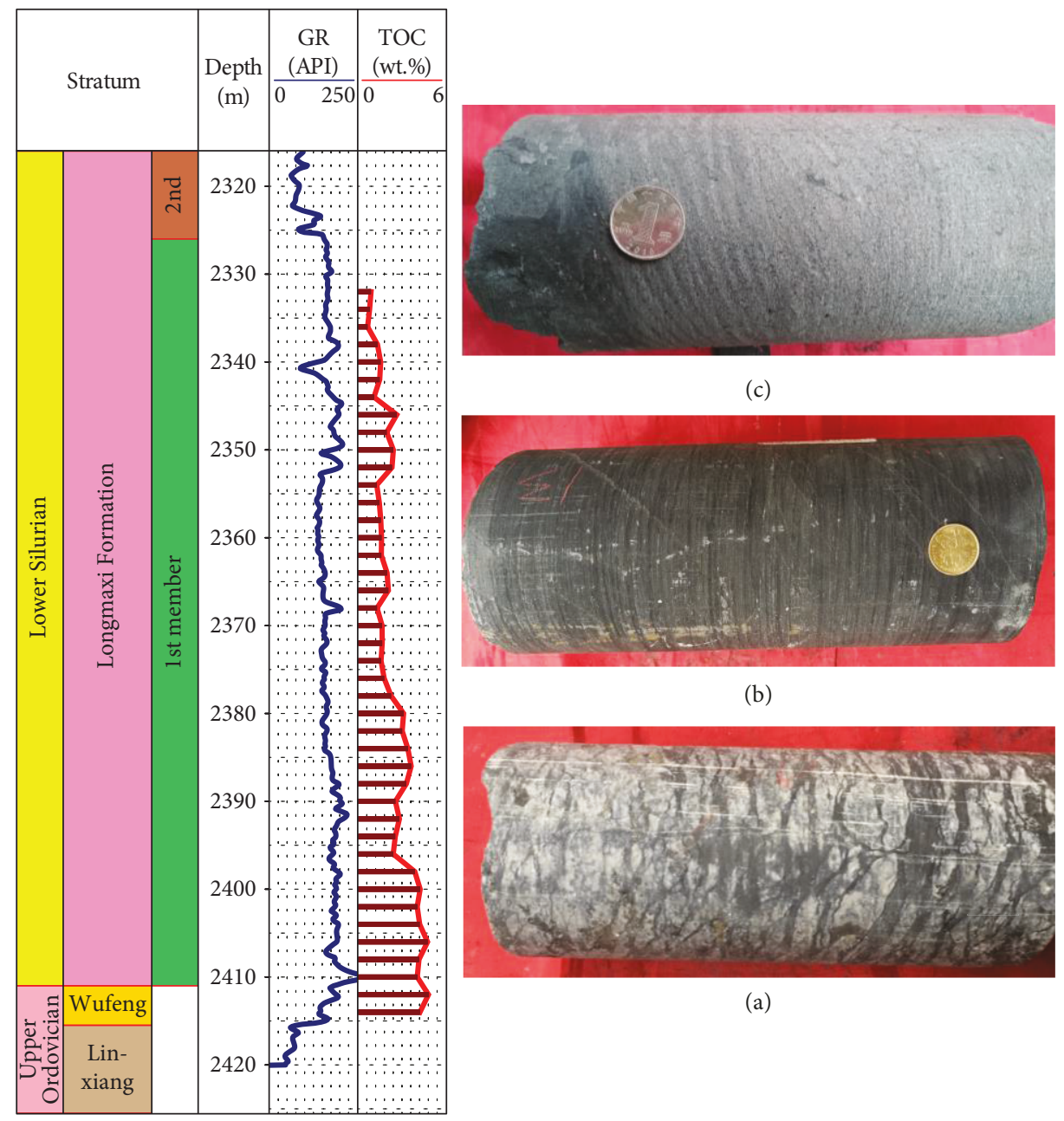

(c)

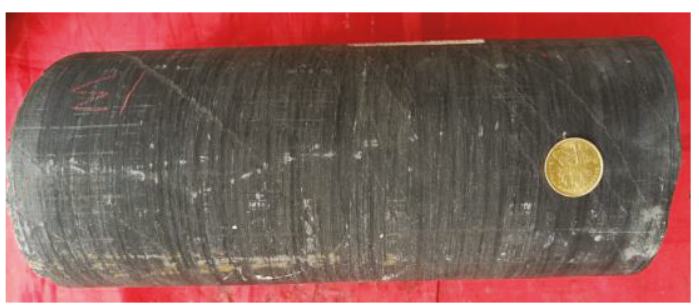

(b)

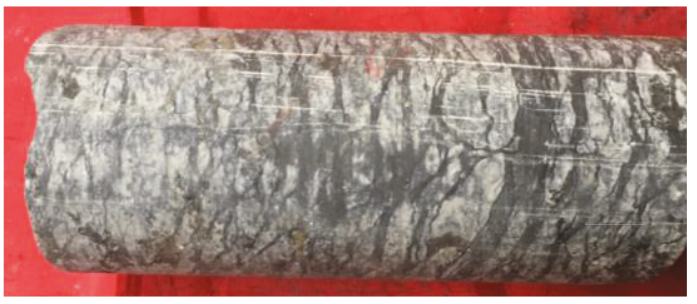

(a)

FIGURE 3: Stratigraphic column and core photos of the Upper Ordovician Linxiang Formation, the Upper Ordovician Wufeng Formation no. 1 section of the Lower Silurian Longmaxi Formation, and the no. 2 section of the Lower Silurian Longmaxi Formation in Jiaoye-1 Well. (a) The Upper Ordovician Linxiang greenish-grey warty limestone, $2419 \mathrm{~m}$; (b) the Upper Ordovician Wufeng Formation no. 1 section of the Lower Silurian Longmaxi black siliceous shale, 2401 m; (c) the no. 2 section of the Lower Silurian Longmaxi grey silty shale, 2319 m. See Figure 1 for the well locations.

TABLE 1: The number, block, and well name of samples used in the triaxial unloading tests. See Figure 1 for the well locations.

\begin{tabular}{lccccc}
\hline Number & Block & Well & Number & Block & Well \\
\hline 1 & Pengshui & Pengye-1 & 9 & Shizhu & Jianshen-1 \\
2 & Dingshan & Dingshan-1 & 10 & Shizhu & Jianshen-1 \\
3 & Dingshan & Dingshan-1 & 11 & Shizhu & Jianshen-1 \\
4 & Dingshan & Dingshan-1 & 12 & Shizhu & Jianshen-1 \\
5 & Dingshan & Dingshan-1 & 13 & Shizhu & Jianshen-1 \\
6 & Dingshan & Dingshan-1 & 14 & Shizhu & Jianshen-1 \\
7 & Dingshan & Dingshan-1 & 15 & Shizhu & Jianshen-1 \\
8 & Shizhu & Jianshen-1 & 16 & Shizhu & Jianshen-1 \\
\hline
\end{tabular}

FIB-SEM are easier to observe in the FIB-HIM. In FIB-HIM images, the clay minerals and the carbonates are both light gray, while the organic matter is dark gray. Although the pores, quartz, and feldspar are all black, the pores have $3 \mathrm{D}$ features, while the quartz and feldspar do not. In this study,
TABLE 2: The number, well name, and formation of samples used in the permeability tests parallel and perpendicular to the stratification plane. See Figure 1 for the well locations.

\begin{tabular}{lccccc}
\hline Number & Well & Formation & Number & Well & Formation \\
\hline 1 & Jiangye-1 & Wangyinpu & 12 & Pengye-1 & Longmaxi \\
2 & Jiangye-1 & Wangyinpu & 13 & Pengye-1 & Longmaxi \\
3 & Jiangye-2 & Wangyinpu & 14 & Pengye-1 & Longmaxi \\
4 & Jiangye-2 & Wangyinpu & 15 & Pengye-1 & Longmaxi \\
5 & Jiangye-2 & Wangyinpu & 16 & Pengye-1 & Longmaxi \\
6 & Jiangye-2 & Wangyinpu & 17 & Pengye-1 & Longmaxi \\
7 & Jiangye-2 & Wangyinpu & 18 & Pengye-1 & Longmaxi \\
8 & Jiangye-2 & Wangyinpu & 19 & Pengye-1 & Longmaxi \\
9 & Jiangye-2 & Wangyinpu & 20 & Pengye-1 & Longmaxi \\
10 & Jiangye-2 & Wangyinpu & 21 & Pengye-1 & Longmaxi \\
11 & Pengye-1 & Longmaxi & 22 & Pengye-1 & Longmaxi \\
\hline
\end{tabular}


TABLE 3: The number, depth, and formation of the samples used in the inclusion analysis. See Figure 1 for the well locations.

\begin{tabular}{lclccc}
\hline Number & $\begin{array}{c}\text { Depth } \\
(\mathrm{m})\end{array}$ & Formation & Number & $\begin{array}{c}\text { Depth } \\
(\mathrm{m})\end{array}$ & Formation \\
\hline 1 & 1343.26 & Xinkailing & 4 & 2608.42 & Wangyinpu \\
2 & 1349.01 & Xinkailing & 5 & 2621.40 & Wangyinpu \\
3 & 1351.61 & Xinkailing & 6 & 2635.25 & Wangyinpu \\
\hline
\end{tabular}

the samples used for the FIB-HIM tests were from the Longmaxi Formation shale at a depth of $2405 \mathrm{~m}$ in Jiaoye-1 Well in the Jiaoshiba block and processed by Ar-ion polishing before the experiment.

3.4. Identification of Inclusions. There are six samples taken from Jiangye-1 Well in the Lower Yangtze, of which three were from the Upper Ordovician Xinkailing Formation and the other were from the Lower Cambrian Wangyinpu Formation, as shown in Table 3. A Leica polarizing microscope and a THMSG600 geological heating/freezing system were used for the identification of inclusions in the samples.

\section{Results and Discussion}

\subsection{In the Anticline}

4.1.1. The Angle of the Limbs. According to the limb angles of the fold deformation, the deformation strength of the positive structural style can be represented. The greater the limb angle is, the weaker is the deformation and the fewer are the fractures produced by tectonic extrusion, leading to lower shale gas content. In contrast, the smaller the limb angle is, the stronger is the deformation, which causes considerable development of large fractures in various structural areas and accelerates the dissipation of shale gas [34].

In previous studies, the deformation strength is divided by standards of $70^{\circ}$ and $120^{\circ}$. The deformation is weak if the limb angle is $120^{\circ}-180^{\circ}$, intermediate if the angle is $70^{\circ}-$ $120^{\circ}$, and strong if the angle is less than $70^{\circ}$ [35-37]. Another study gathered limb angle data in typical shale gas blocks. The Jiaoshiba and Fushun-Yongchuan blocks are anticlines with limb angles of $120^{\circ}-180^{\circ}$, which leads to great preservation conditions. The formation pressure coefficient of Jiaoye-1 in Jiaoshiba and Yang-101 in Fushun-Yongchuan is in the range of 1.5-2.2 [38]. The angle of the limbs of the high and steep Huaying Mountain anticline is $70-120^{\circ}$ in the eastern Sichuan Basin. Because of the strong extrusion, fractures frequently developed in the Upper Ordovician Wufeng Formation and in the Lower Silurian Longmaxi Formation in the Huadi-1 Well and they control the reservoir properties of the shale along with the organic pores. The shale gas migrates upwards along the fractures and stratifications. Due to the better sealing of the overlaying strata in the Silurian, mixture shale gas reservoir composed of adsorbed gas and free gas is formed through the conventional gas mechanism [38]. The Yuye-1 Well in the southeast Sichuan experienced a stronger extrusion for its location outside the
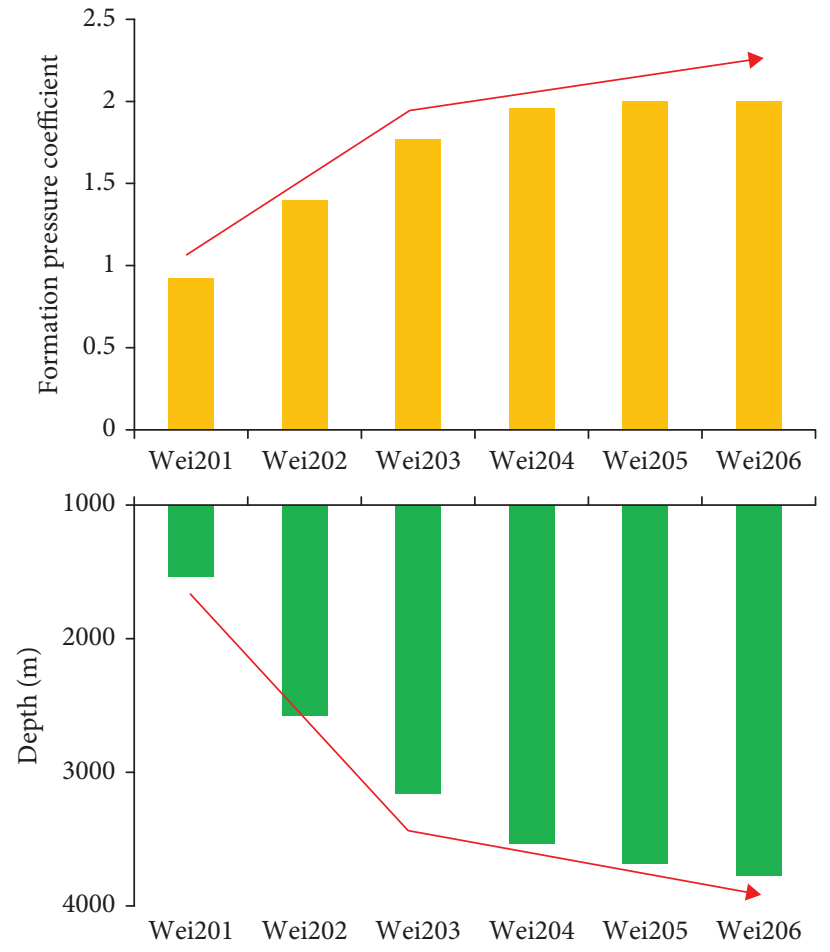

Figure 4: Correlation diagram of the burial depth and the formation pressure coefficient of the typical wells in the Weiyuan block. See Figure 1 for the well locations.

Sichuan Basin. In addition, its limb angle is less than $70^{\circ}$ and high-angle fractures developed, resulting in a large dissipation of shale gas and the extremely low gas content of the well [39].

\subsubsection{Burial Depth}

(1) Phenomenon. In addition to the properties of the anticline, burial depth has an important influence on shale gas enrichment. When shale is uplifted as a whole, the horizontal stress is constant and the burial depth gradually decreases. When shale is raised to a certain depth, the shale will break up with massive loss of shale gas, resulting in the pressure coefficient of the formation reduction $[31,40,41]$. The real-time drilling data shows the same phenomenon. In this paper, six wells, which are all in the Weiyuan anticline in the southern Sichuan Basin, were evaluated; they share a similar material basis and were drilled from the top to the limb, from shallow to deep. As shown in Figure 4, the pressure coefficient of the formation gradually increases with the increase in the burial depth.

(2) The Breaking Depth Calculation of Shale under Uplift. Theoretically, this is the confining pressure in the test constant, which is required to break the same rock in the same horizontal stress field. The breaking confining pressure under different stress fields can be modeled with unloading experiments, and then, an equation of breaking confining pressure and horizontal stress can be established. The breaking 
TABLE 4: The results of the triaxial unloading experiments, including the breaking confining pressure and the burial depth calculated when a certain axial pressure is applied to the rock (namely, the horizontal stress). See Figure 1 for the well locations.

\begin{tabular}{|c|c|c|c|c|c|c|}
\hline No. & Block & Fm. & Well & $\begin{array}{c}\text { Axial pressure } \\
\text { (horizontal stress) (MPa) }\end{array}$ & $\begin{array}{l}\text { Breaking confining } \\
\text { pressure }(\mathrm{MPa})\end{array}$ & $\begin{array}{l}\text { Burial depth translated from } \\
\text { the confining pressure }(\mathrm{m})\end{array}$ \\
\hline 1 & Pengshui & $\mathrm{S}_{1} \mathrm{l}$ & Pengye-1 & 140.0 & 16.6 & 1692.2 \\
\hline 2 & Dingshan & $\mathrm{S}_{1} 1$ & Dingshan-1 & 159.3 & 6.8 & 697.0 \\
\hline 3 & Dingshan & $\mathrm{S}_{1} \mathrm{l}$ & Dingshan-1 & 163.2 & 11.1 & 1126.5 \\
\hline s4 & Dingshan & $\mathrm{S}_{1} \mathrm{l}$ & Dingshan-1 & 207.0 & 20.0 & 2038.7 \\
\hline 5 & Dingshan & $\mathrm{S}_{1} 1$ & Dingshan-1 & 182.3 & 20.8 & 2124.7 \\
\hline 6 & Dingshan & $\mathrm{S}_{1} \mathrm{l}$ & Dingshan-1 & 216.0 & 24.0 & 2444.6 \\
\hline 7 & Dingshan & $\mathrm{S}_{1} 1$ & Dingshan-1 & 254.0 & 30.0 & 3058.1 \\
\hline 8 & Shizhu & $\mathrm{S}_{1} 1$ & Jianshen-1 & 72.9 & 0.1 & 5.1 \\
\hline 9 & Shizhu & $\mathrm{S}_{1} 1$ & Jianshen-1 & 74.6 & 1.3 & 136.6 \\
\hline 10 & Shizhu & $S_{1} 1$ & Jianshen-1 & 94.4 & 7.1 & 726.8 \\
\hline 11 & Shizhu & $\mathrm{S}_{1} 1$ & Jianshen-1 & 114.1 & 7.5 & 762.5 \\
\hline 12 & Shizhu & $S_{1} 1$ & Jianshen-1 & 114.1 & 10.3 & 1054.0 \\
\hline 13 & Shizhu & $S_{1} 1$ & Jianshen-1 & 134.1 & 15.2 & 1550.5 \\
\hline 14 & Shizhu & $\mathrm{S}_{1} \mathrm{l}$ & Jianshen-1 & 137.6 & 18.3 & 1862.4 \\
\hline 15 & Shizhu & $\mathrm{S}_{1} \mathrm{l}$ & Jianshen-1 & 158.3 & 26.0 & 2648.3 \\
\hline 16 & Shizhu & $\mathrm{S}_{1} 1$ & Jianshen-1 & 159.0 & 26.3 & 2678.9 \\
\hline
\end{tabular}

confining pressure can be translated into the burial depth according to the following equation.

$$
H=P \times \frac{1000}{9.81}
$$

where $H$ is the burial depth, with the unit of $\mathrm{m}$, and $P$ is the breaking confining pressure, with the unit of $\mathrm{MPa}$.

The horizontal stress field is simulated by the axial pressure, and the results of triaxial unloading tests are shown in Table 4. The results show that the confining and axial pressures are positively proportional when the shale fractured. The high axial pressure corresponds to the high breaking confining pressure, indicating that in the high horizontal stress zone, the burial depth is greater when the breaking of shale occurs.

Using statistics of the experimental data, Figure 5 is used to obtain the following mathematical regression equation of the burial depth $(H, \mathrm{~m})$ and the horizontal stress $(S, \mathrm{MPa})$ when the rock breaks: $H=15.404 S-754.41$ (with a correlation coefficient $R^{2}=0.6834$ ). Through the recovery of the regional stress field, the present horizontal stress in one block under the anticline background can be obtained. Through the regression equation, the depth of the large amount of gas loss caused by the shale fracture during the anticlinal uplift can be calculated.

4.2. The Combination of the Anticline and Adjacent Syncline. The tectonic structure formed by the anticline and adjacent synclines easily exists in blocks that are subjected to compression but not large-scale erosion. This structural type is more common in the southern part of the Sichuan Basin [25, 26, 41]. Here, three aspects of the shale gas migration (dynamic, channel, and evidence) are discussed and the enrichment regulation of shale gas is studied in

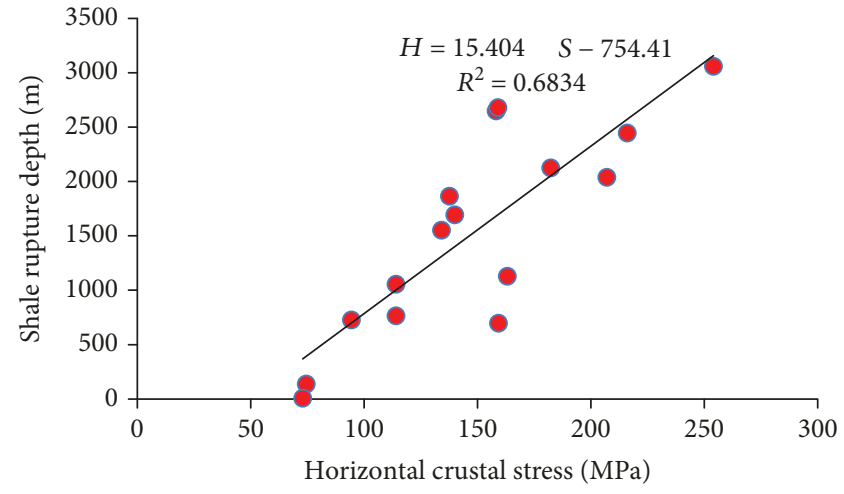

Figure 5: Correlation diagram of the burial depth and the horizontal stress when the shale fractured in the triaxial unloading tests. See Figure 1 for the well locations.

the structural combination of the anticline and the contiguous syncline.

4.2.1. Migration Dynamics. In the structural combination, there is an obvious difference in the formation pressure coefficient between the anticline and the adjacent syncline. As shown in Figure 6, there is an anticline and a syncline in the Dingshan block at the same time. In this paper, the burial depth of the drilling and the formation pressure coefficient are measured and the residual formation pressure is calculated. As shown in Table 5, the residual pressure difference of the two wells is $23.81-1.67=22.14 \mathrm{MPa}$. In conventional oil and gas reservoirs, the residual pressure difference between the source rock and the reservoir of the overpressure basin is $20-30 \mathrm{MPa}$, which can cause the efficient migration of natural gas. In shale gas reservoirs, the difference of the pressure coefficient between the anticline and the adjacent syncline can also provide sufficient force for the migration 


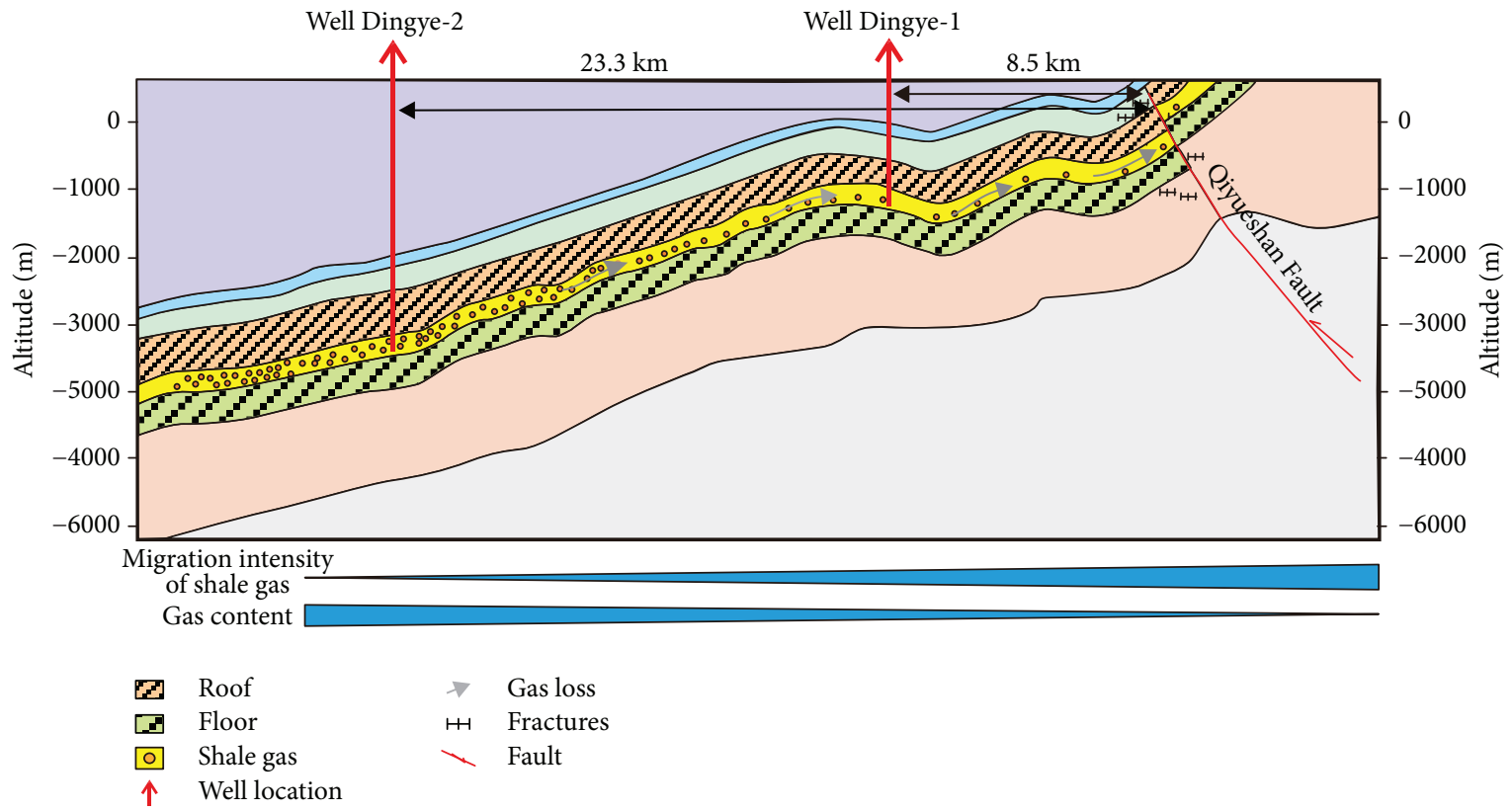

FIgure 6: The cross-section of the structural characteristics of the Dingshan block and the structural location of Dingye-1 and Dingye-2 Wells. Modified from Wei et al. (2017). See Figure 1 for the well locations.

TABLE 5: The burial depth, formation pressure coefficient, and residual formation pressure of the target in Dingye-1 and Dingye-2 Wells in the Dingshan block. See Figure 1 for the well locations.

\begin{tabular}{lccccc}
\hline Structural type & Well & Depth $(\mathrm{m})$ & $\begin{array}{c}\text { Formation } \\
\text { pressure coefficient }\end{array}$ & $\begin{array}{c}\text { Shale gas production } \\
\left(\times 10^{4} \mathrm{~m}^{3} / \mathrm{t}\right)\end{array}$ & $\begin{array}{c}\text { Residual formation } \\
\text { pressure }(\mathrm{MPa})\end{array}$ \\
\hline Anticline & Dingye-1 & 2125.76 & 1.08 & 3.45 & 1.67 \\
Syncline & Dingye-2 & 4417.43 & 1.55 & 10.5 & 23.81 \\
\hline
\end{tabular}

of natural gas from the syncline to the anticline in the shale layers $[42,43]$.

\subsubsection{Migration Channel}

(1) Lateral and Vertical Permeability. The results of the lateral and vertical permeability tests of the shales in the Jiangye-1 Well and Jiangye-2 Well of the Lower Cambrian Wangyinpu Formation and the Pengye-1 Well of the Lower Silurian Longmaxi Formation are shown in Figures 7 and 8. The result indicates that the permeability parallel to the stratification plane is 1-40 times higher than the permeability perpendicular to the stratification plane, even in different shale strata.

(2) The Connected Organic Pores. In this study, the FIB-HIM experiments were carried out on the organic-rich shale of the Lower Silurian Longmaxi Formation in the Jiaoye-1 well of the Jiaoshiba block. The experimental results are shown in Figure 9. The results show that more connected pores developed in the organic matter of the shale, and the study of Wang et al. (2016a, 2016b) also suggested that the primary connected channel is provided more by the organic pores in the shale than the inorganic pores $[44,45]$. From the permeability parallel and perpendicular to the stratification plane and from the FIB-HIM images, it is shown that there is a dominant channel in the shale formation, which is composed of organic pores and the stratification plane and the main direction of shale gas migration is parallel to the stratification plane.

(3) Quantitative Characterization of Migration Pathway Connectivity. A spontaneous imbibition experiment conducted by the previous studies is used to quantitatively evaluate whether percolation can occur in the migration channel. Spontaneous imbibition refers to the process of spontaneous replacement of a fluid with nonwettability by another fluid with wettability under the capillary force in rock pores [46]. The slope of the spontaneous imbibition curve can be used to quantitatively evaluate pore connectivity in shale reservoirs. Reservoirs with high porosity connectivity $(P>0.28$, where $P$ is the average probability of connectivity) have a rate of 0.5 . When $P$ is equal to 0.2488 (the percolation critical value), the rate is 0.26 [47].

Huang et al. (2017) sampled the organic-rich shale in the Longmaxi Formation of the Dingshan block at two different depths to conduct the spontaneous imbibition experiment [48]. The samples are cube shaped with a border length of 


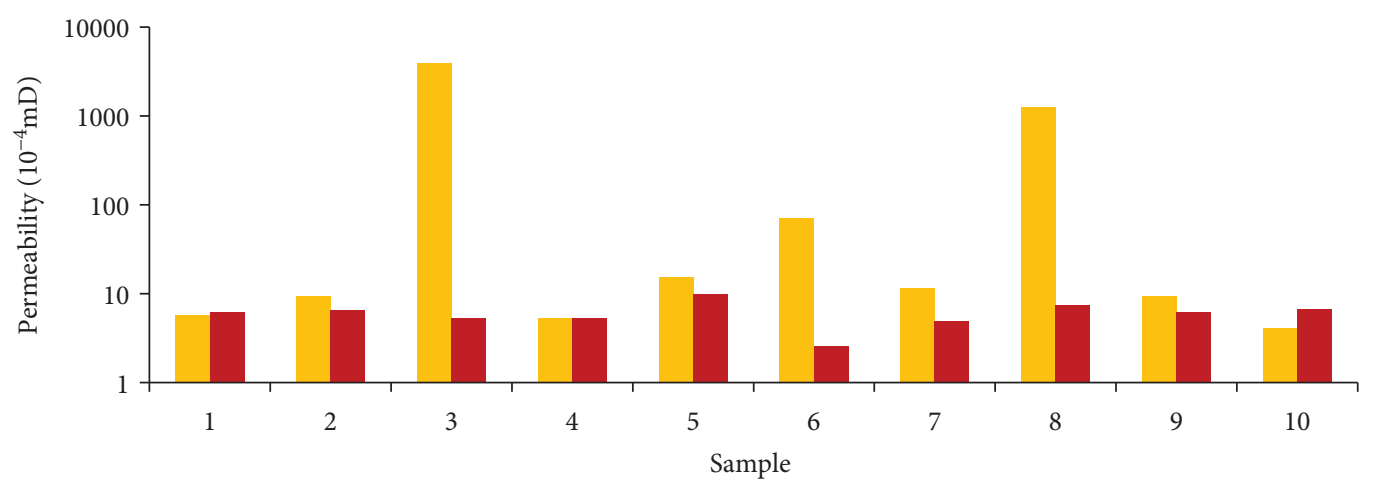

Lateral permeability

- Vertical permeability

(a)

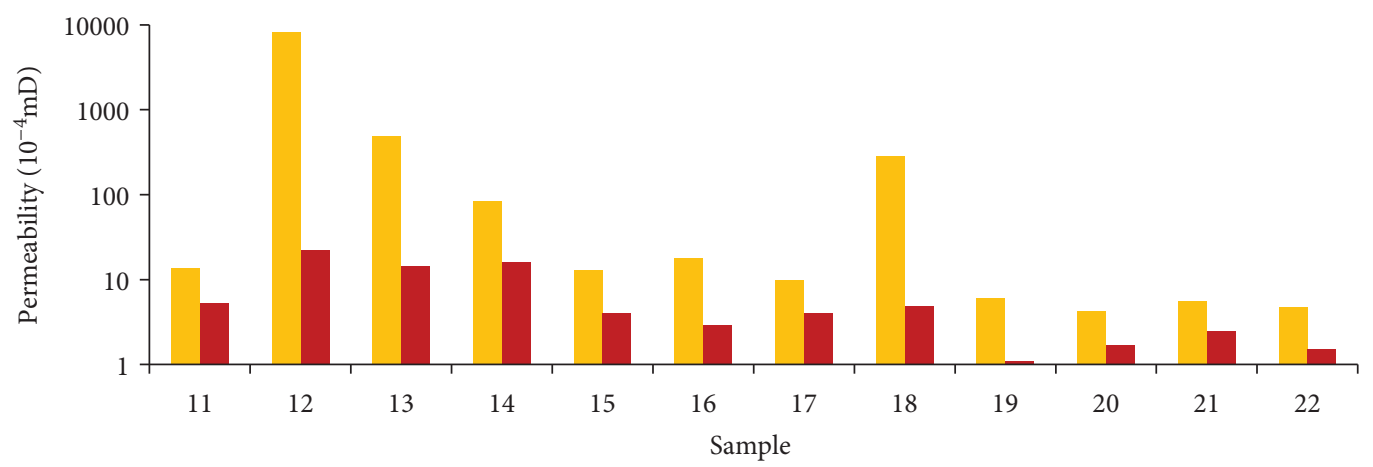

- Lateral permeability

- Vertical permeability

(b)

Figure 7: Histograms of the lateral and vertical permeability. (a) Samples of the Lower Cambrian Wangyinpu Formation shale, from the Jiangye-1 Well and Jiangye-2 Well. (b) Samples of the Lower Silurian Longmaxi Formation shale, from the Pengye-1 Well. See Figure 1 for the well locations.

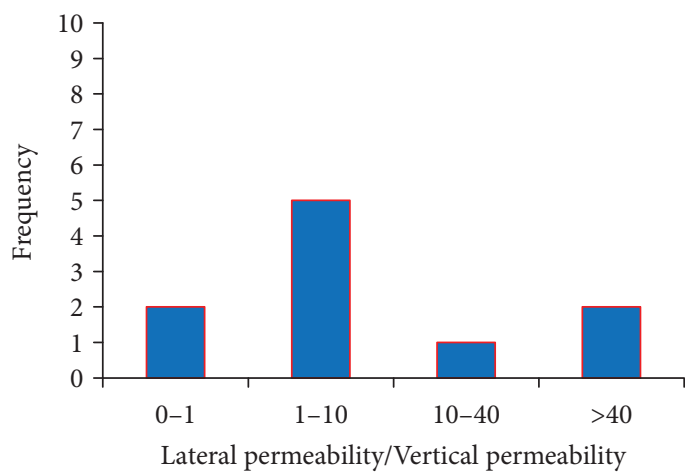

(a)

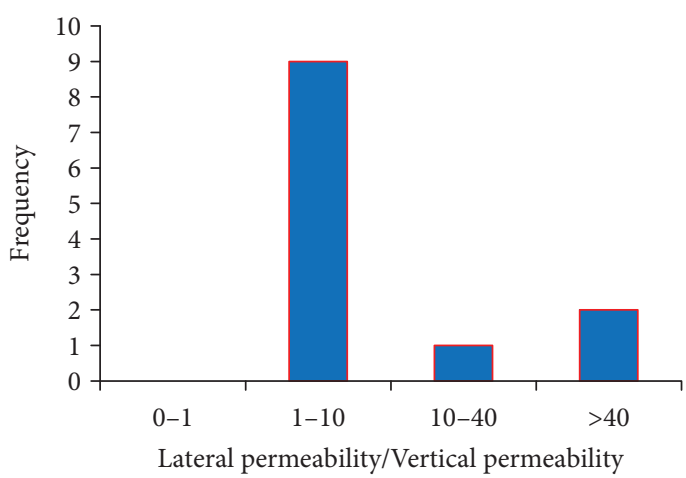

(b)

Figure 8: The ratio statistics between lateral and vertical permeability. (a) Samples of the Lower Cambrian Wangyinpu Formation shale, from the Jiangye-1 Well and Jiangye-2 Well. (b) Samples of the Lower Silurian Longmaxi Formation shale, from Pengye-1 Well. See Figure 1 for the well locations.

approximately $1 \mathrm{~cm}$. There are 4 samples in total selected from each direction (parallel or perpendicular to the stratification plane) at each depth, from which the curve rates of the spontaneous imbibition perpendicular to the stratification plane are 0.234 and 0.181 , respectively, and parallel rates are 0.441 and 0.275 , respectively. This suggests that the shale connectivity is higher in the horizontal direction than in the vertical direction. In addition, the curve rate of the spontaneous imbibition slope in the lateral direction is more than 0.26 , which is the percolation critical value, which indicates that 

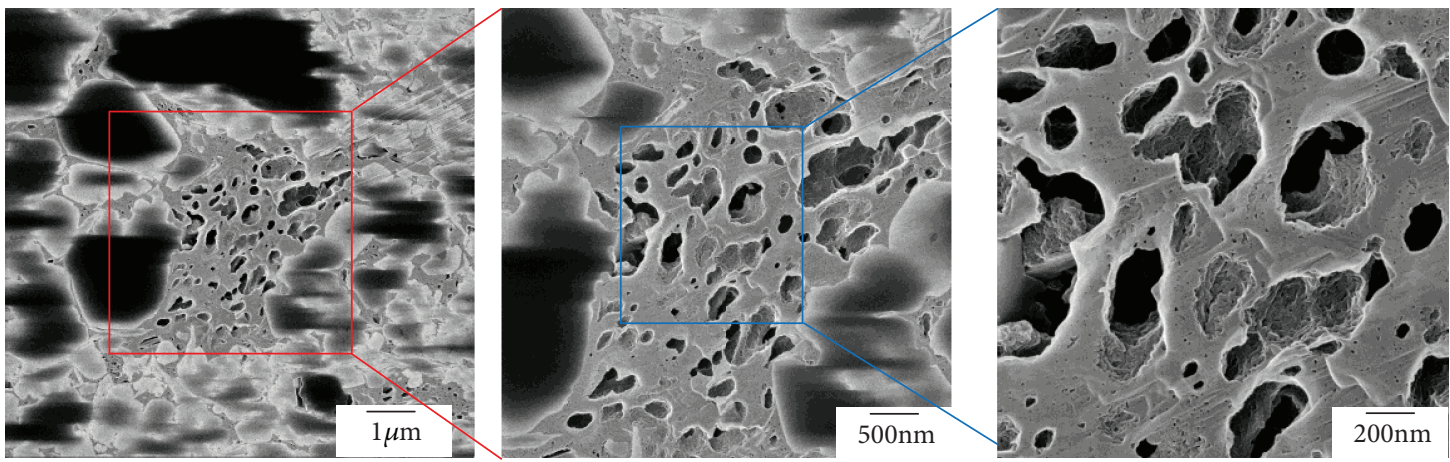

FIGURE 9: FEB-HIM photos of the organic-rich shale of the Jiaoye-1 Well in the Jiaoshiba block in the Lower Silurian Longmaxi Formation. The burial depth of the samples is $2405 \mathrm{~m}$, the TOC is $4.44 \%$, and the Ro is $0.58 \%$. See Figure 1 for the well locations.

the flow of the natural gas can occur in the lateral direction of the shale. However, because the rate is less than 0.5 , the curve rate of the highly connected pores has not yet been reached; thus, the percolation migration occurs over a short distance.

4.2.3. Migration Evidence. Fluid inclusions are an effective source of paleogeological fluid information and have become an important means to study paleotemperature and paleopressure, the properties of paleofluids, and oil and gas fluid tracing. Fluid inclusions are commonly found in shale. Based on laser Raman spectroscopy and microthermometry analysis of fluid inclusions, Gao et al. identified inclusions with a high density of methane in samples of quartz and calcite veins in the shale of the Wufeng and Longmaxi Formations in the Jiaoshiba gas field and they found that there are 3 phases of the fluid charging activities [49]. Wei et al. analyzed the homogeneous temperature of fluid inclusions in Dingye-2 Well and found that there are at least 3 phases of fluid charging in the fractures in the shale of Wufeng and Longmaxi Formations [50]. The paper analyzes the inclusions in the Upper Ordovician Xinkailing Formation and the Lower Cambrian Wangyinpu Formation shale in the Jiangye-1 Well of the Xiuwu Basin and found that there is a large amount of inclusions containing methane and two-phase brine in the quartz minerals with secondary enlargement and microfissures and there are at least 2 phases of fluid charging. These findings confirm the widespread existence of shale gas migration (Figure 10).

\subsection{Marine Shale Gas Accumulation Model under the} Anticline Backgrounds. These indirect evidences from migration force, migration channel, and migration evidence can prove that in the structural combination formed by syncline and adjacent anticline, the compression and uplift of anticline can form cracks, which lead to the escape of shale gas. Driven by the difference of formation pressure, natural gas in adjacent syncline shale series can migrate from syncline to anticline along the stratigraphic plane and organic holes by short-distance displacement stepped migration, which realizes the large-scale supplement of syncline shale gas to anticline. The migration process is short distance and stair type, which caused the large-scale movement of the shale gas from the syncline to the anticline.
In the structural combination, the anticline burial depth is relatively shallow, making the drilling costs lower, but the formation pressure coefficient is relatively lower as well. While the deeper burial depth in the syncline is accompanied by a higher formation pressure coefficient and higher shale gas productivity, there are higher drilling costs. Thus, the more optimal well position should be arranged in the deeper syncline with an allowance for the drilling cost. An enrichment model of marine shale gas in anticlines is shown in Figure 11.

\section{Conclusions}

In this paper, the target layer is the Lower Cambrian and the Upper Ordovician-Lower Silurian marine shale in the Yangtze region, Southern China. The study areas include the Jiaoshiba, Pengshui, Shizhu, Huaying Mountain, Fushun Yongchuan, and Weiyuan blocks in the Sichuan Basin in Upper Yangtze and the Xiuwu Basin in Lower Yangtze. In the two tectonic settings of the anticline and the combination of the anticline and the contiguous syncline, the enrichment regulation of shale gas is analyzed with triaxial unloading tests, the permeability test parallel and perpendicular to the stratification plane, FIB-HIM experiments, and inclusions analysis. Thus, the following conclusions are drawn:

(1) The greater the anticline limb angle is, the more favorable are the conditions for shale gas enrichment. The deformation strength is identified by standards of $70^{\circ}$ and $120^{\circ} \mathrm{limb}$ angles. The deformation is weak if the limb angle is $120-180^{\circ}$, intermediate if the angle is $70-120^{\circ}$, and strong if the angle is less than $70^{\circ}$

(2) In anticlines, during uplift, the shale is fractured massively and in a concentrated manner at a certain depth and horizontal stress field, causing large losses of shale gas. The greater the horizontal stress is, the deeper is the breaking burial depth of the seal. The mathematical regression equation of the burial depth $(H, \mathrm{~m})$ and the horizontal stress $(\mathrm{S}, \mathrm{MPa})$ when the rock breaks is given by $H=15.404 S-754.41$ (with a correlation coefficient $R^{2}=0.6834$ )

(3) The permeability is much higher in the direction parallel to the stratification plane than in the perpendicular direction. Thus, the migration direction 


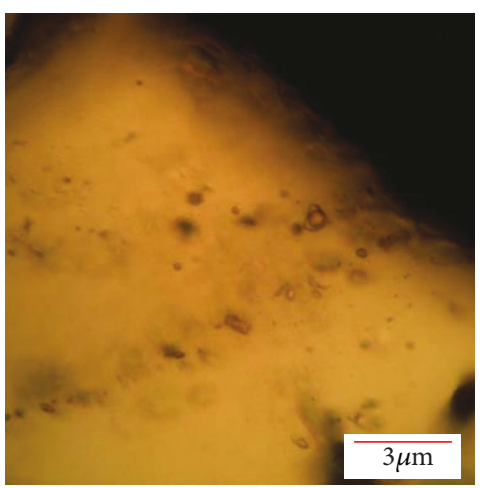

(a)

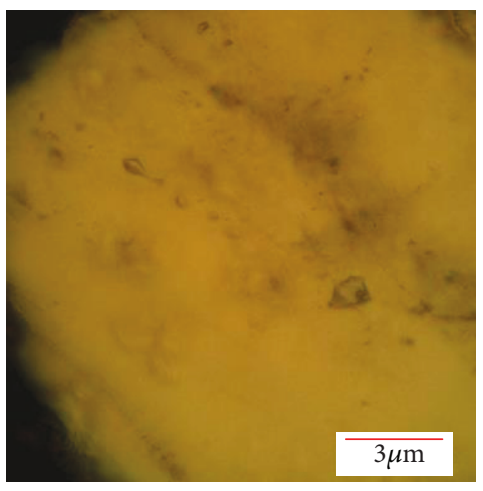

(d)

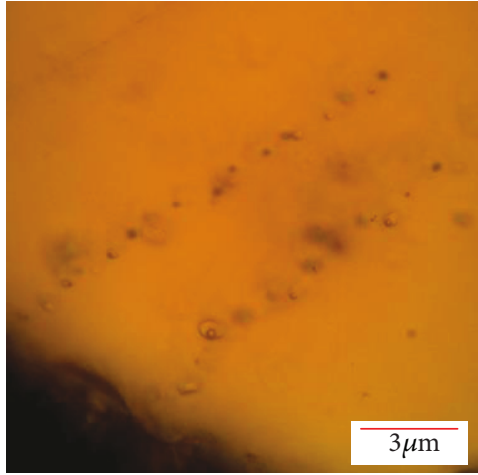

(b)

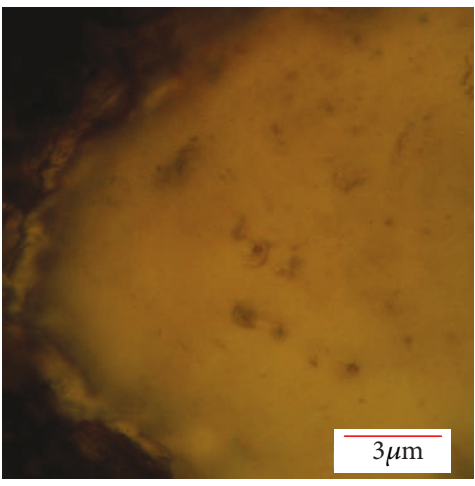

(e)

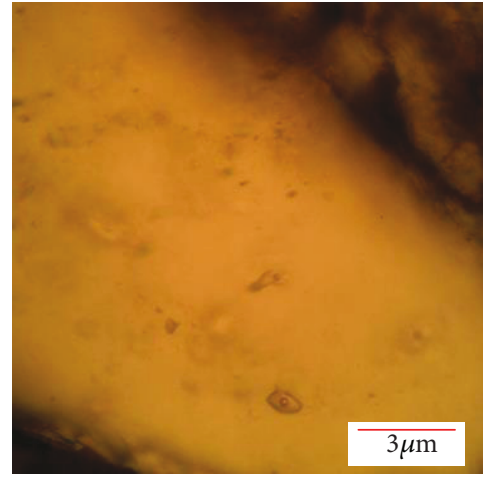

(c)

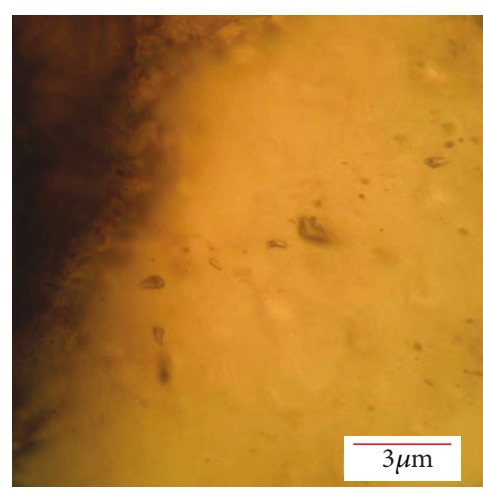

(f)

FIGURE 10: The production and morphological characteristics of fluid inclusions in shale of the Upper Ordovician Xinkailing Formation and the Lower Cambrian Wangyinpu Formation in the Jiangye-1 Well, Xiuwu Basin. (a) Transmissive photo of elliptical methane inclusions in the quartz minerals of secondary enlargement, Jiangye-1 Well, $1343.26 \mathrm{~m}$ depth, the Upper Ordovician Xinkailing Formation. (b) Transmissive photo of methane inclusions of irregular forms in the quartz minerals of secondary enlargement, Jiangye-1 Well, $1349.01 \mathrm{~m}$ depth, the Upper Ordovician Xinkailing Formation. (c) Transmissive photo of brine inclusions of irregular forms in the quartz minerals of secondary enlargement, Jiangye-1 Well, $1351.61 \mathrm{~m}$ depth, the Upper Ordovician Xinkailing Formation. (d) Transmissive photo of methane inclusions of irregular forms in the quartz minerals of secondary enlargement, Jiangye-1 Well, $2621.40 \mathrm{~m}$ depth, the Lower Cambrian Wangyinpu Formation. (e) Transmissive photo of brine inclusions of irregular forms in the quartz fractures, Jiangye-1 Well, $2621.40 \mathrm{~m}$ depth, the Lower Cambrian Wangyinpu Formation. (f) Transmissive photo of brine inclusions of irregular forms in the quartz minerals of secondary enlargement, Jiangye-1 Well, $2635.25 \mathrm{~m}$ depth, the Lower Cambrian Wangyinpu Formation. See Figure 1 for the well locations.

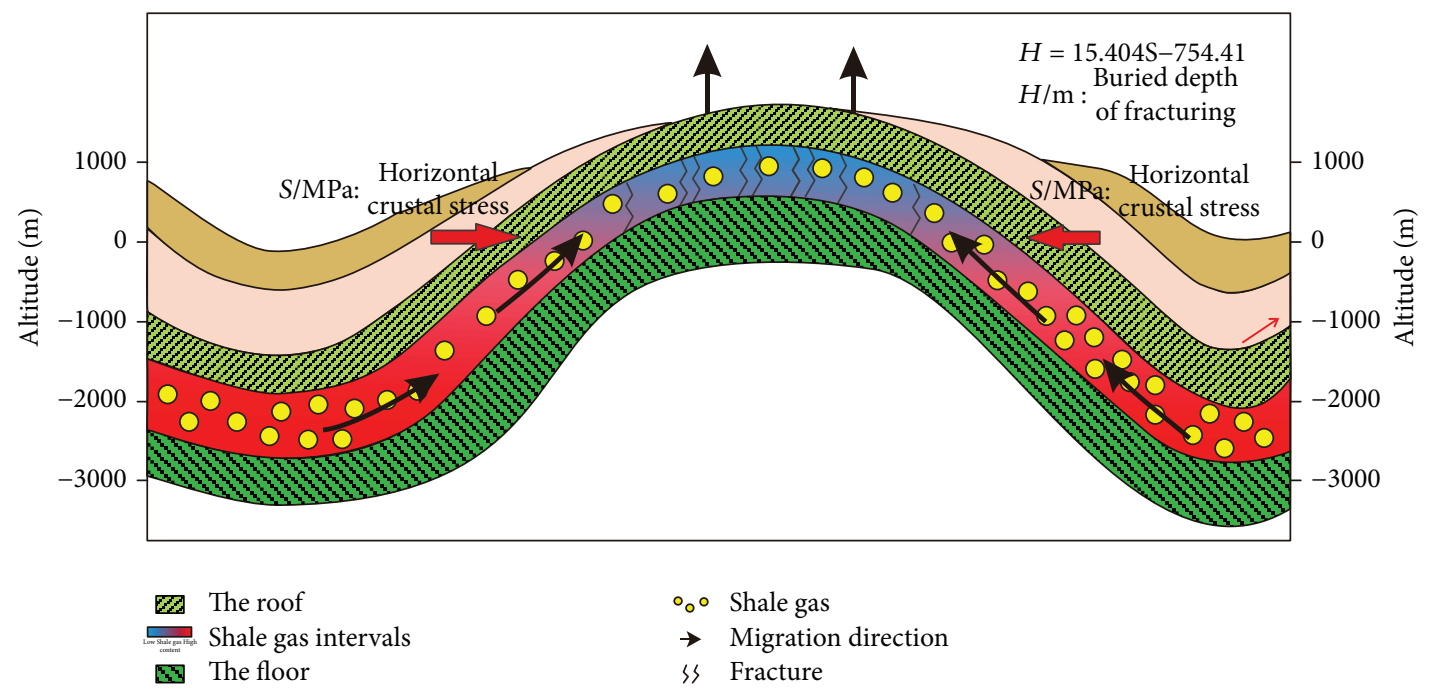

Figure 11: Accumulation model of marine shale gas in anticlines. 
is primarily along the stratification plane and the stratification plane and the organic pores constitute the migration channel for the shale gas. When the anticline and the adjacent syncline exist at the same time, there will be fractures developed in the anticline that cause the shale gas dissipation. Driven by the difference of the formation pressure coefficient, the short-distance stair-type migration occurs from the syncline to the adjacent anticline. The optimal well positions should be arranged in the deeper syncline with an allowance for the drilling cost

\section{Data Availability}

The data used to support the findings of this study are included within the article.

\section{Additional Points}

Highlights. (i) The larger the anticline limb angle is, the more favorable is the accumulation for shale gas; (ii) in anticlines, during uplifting, shale is extensively fractured and the fractures are concentrated within a certain depth range and horizontal stress field, causing considerable shale gas losses; and (iii) the bedding plane and organic pores provide the migration pathways of shale gas. Driven by the difference in the formation pressure coefficient, short-distance stair-type migration occurs from the syncline to the adjacent anticline.

\section{Disclosure}

Part of this work has been presented as an abstract at GSA Annual Meeting in Indianapolis, Indiana, USA-2018.

\section{Conflicts of Interest}

The authors declare that there are no conflicts of interest regarding the publication of this paper.

\section{Acknowledgments}

The support from the National Science and Technology Major Project (no. 2017ZX05035-002), the Science Foundation of the Ministry of Land and Resources of the People's Republic of China (no. 12120114046701), the National Natural Science Foundation of China (no. 41472112 and no. 41728004), the open fund (PLC20190503) of the State Key Laboratory of Oil and Gas Reservoir Geology and Exploitation (Chengdu University of Technology), and the open fund from the Sinopec Key Laboratory of Shale Oil/Gas Exploration and Production Technology is gratefully acknowledged.

\section{References}

[1] J. B. Curtis, "Fractured shale-gas systems," AAPG Bulletin, vol. 86, no. 11, pp. 1921-1938, 2002.

[2] S. L. Montgomery, D. M. Jarvie, K. A. Bowker, and R. M. Pollastro, "Mississippian Barnett Shale, Fort Worth basin, north-central Texas: gas-shale play with multi-trillion cubic foot potential," AAPG Bulletin, vol. 89, no. 2, pp. 155-175, 2005.

[3] D. Warlick, "Gas shale and CBM development in North America," Oil and Gas Financial Journal, vol. 3, no. 11, pp. 1-5, 2006.

[4] W. Ji, Y. Song, Z. Jiang et al., "Fractal characteristics of nano-pores in the Lower Silurian Longmaxi shales from the Upper Yangtze platform, South China," Marine and Petroleum Geology, vol. 78, pp. 88-98, 2016.

[5] W. Ji, Y. Song, Z. Jiang, X. Wang, Y. Bai, and J. Xing, "Geological controls and estimation algorithms of lacustrine shale gas adsorption capacity: a case study of the Triassic strata in the Southeastern Ordos Basin, China," International Journal of Coal Geology, vol. 134-135, pp. 61-73, 2014.

[6] C. Zou, D. Dong, Y. Wang et al., "Shale gas in China: characteristics, challenges and prospects (I)," Petroleum Exploration and Development, vol. 42, no. 6, pp. 753-767, 2015.

[7] C. Zou, D. Dong, Y. Wang et al., "Shale gas in China: characteristics, challenges and prospects (II)," Petroleum Exploration and Development, vol. 43, no. 2, pp. 182-196, 2016.

[8] X. Tang, Z. Jiang, Z. Li et al., "The effect of the variation in material composition on the heterogeneous pore structure of highmaturity shale of the Silurian Longmaxi Formation in the Southeastern Sichuan Basin, China," Journal of Natural Gas Science and Engineering, vol. 23, pp. 464-473, 2015.

[9] X. Tang, Z. Jiang, S. Jiang, P. Wang, and C. Xiang, "Effect of organic matter and maturity on pore size distribution and gas storage capacity in high-mature to post-mature shales," Energy \& Fuels, vol. 30, no. 11, pp. 8985-8996, 2016.

[10] X. Tang, Z. Jiang, S. Jiang, L. Cheng, and Y. Zhang, "Characteristics and origin of in-situ gas desorption of the Cambrian Shuijingtuo Formation shale gas reservoir in the Sichuan Basin, China," Fuel, vol. 187, pp. 285-295, 2017.

[11] L. Chen, Z. Jiang, K. Liu et al., "Effect of lithofacies on gas storage capacity of marine and continental shales in the Sichuan Basin, China," Journal of Natural Gas Science and Engineering, vol. 36, pp. 773-785, 2016.

[12] L. Chen, Z. Jiang, K. Liu, J. Tan, F. Gao, and P. Wang, "Pore structure characterization for organic-rich Lower Silurian shale in the Upper Yangtze Platform, South China: a possible mechanism for pore development," Journal of Natural Gas Science and Engineering, vol. 46, pp. 1-15, 2017.

[13] K. Zhang, Z. Jiang, L. Yin et al., "Controlling functions of hydrothermal activity to shale gas content-taking lower Cambrian in Xiuwu Basin as an example," Marine and Petroleum Geology, vol. 85, pp. 177-193, 2017.

[14] K. Zhang, Z. Jiang, X. Xie et al., "Lateral percolation and its effect on shale gas accumulation on the basis of complex tectonic background," Geofluids, vol. 2018, Article ID 5195469, 11 pages, 2018.

[15] K. Zhang, Z. Li, S. Jiang et al., "Comparative analysis of the siliceous source and organic matter enrichment mechanism of the Upper Ordovician-Lower Silurian shale in the Upper-Lower Yangtze area," Minerals, vol. 8, no. 7, 2018.

[16] H. Zhu, J. Deng, X. Jin, L. Hu, and B. Luo, "Hydraulic fracture initiation and propagation from wellbore with oriented perforation," Rock Mechanics and Rock Engineering, vol. 48, no. 2, pp. 585-601, 2015.

[17] H. Y. Zhu, X. C. Jin, J. C. Guo, F. C. An, Y. H. Wang, and $\mathrm{X}$. Lai, "Coupled flow, stress and damage modelling of 
interactions between hydraulic fractures and natural fractures in shale gas reservoirs," International Journal of Oil, Gas and Coal Technology, vol. 13, no. 4, pp. 359-390, 2016.

[18] J. Tang, Y. Li, K. Wang, and Z. Qi, "Comprehensive evaluation of effective preservation zone of Longmaxi Formation shale gas in the Southeast Sichuan Basin," Natural Gas Industry, vol. 35, no. 5, pp. 15-23, 2015.

[19] R. Wang, W. Ding, D. Gong et al., "Gas preservation conditions of marine shale in northern Guizhou area: a case study of the Lower Cambrian Niutitang Formation in the Cen'gong block, Guizhou Province," Oil \& Gas Geology, vol. 37, no. 1, pp. 45-55, 2016.

[20] X. Wei, Y. Li, Z. Wei, R. Liu, G. Yu, and Q. Wang, "Effects of preservation conditions on enrichment and high yield of shale gas in Sichuan Basin and its periphery," Petroleum Geology \& Experiment, vol. 39, no. 2, pp. 147-153, 2017.

[21] W. Zhao, J. Li, T. Yang, S. Wang, and J. Huang, "Geological difference and its significance of marine shale gases in South China," Petroleum Exploration and Development, vol. 43, no. 4, pp. 547-559, 2016.

[22] Z. X. Li, L. Zhang, and C. M. A. Powell, "South China in Rodinia: part of the missing link between Australia-East Antarctica and Laurentia?," Geology, vol. 23, no. 5, pp. 407410, 1995.

[23] Z. X. Li, X. H. Li, H. Zhou, and P. D. Kinny, "Grenvillian continental collision in South China: new SHRIMP U-Pb zircon results and implications for the configuration of Rodinia," Geology, vol. 30, no. 2, pp. 163-166, 2002.

[24] J. Wang and Z. X. Li, "History of Neoproterozoic rift basins in South China: implications for Rodinia break-up," Precambrian Research, vol. 122, no. 1-4, pp. 141-158, 2003.

[25] T. Guo, "Evaluation of highly thermally mature shale-gas reservoirs in complex structural parts of the Sichuan Basin," Journal of Earth Science, vol. 24, no. 6, pp. 863-873, 2013.

[26] T. Guo, "The Fuling shale gas field - a highly productive Silurian gas shale with high thermal maturity and complex evolution history, southeastern Sichuan Basin, China," Interpretation, vol. 3, no. 2, pp. SJ25-SJ34, 2015.

[27] M. Zhu, J. Zhang, M. Steiner, A. Yang, G. Li, and B. Erdtmann, "Sinian-Cambrian stratigraphic framework for shallow-to deep-water environments of the Yangtze platform: an integrated approach," Progress in Natural Science, vol. 13, no. 12, pp. 951-960, 2003.

[28] M. Y. Zhu, L. E. Babcock, and S. C. Peng, "Advances in Cambrian stratigraphy and paleontology: integrating correlation techniques, paleobiology, taphonomy and paleoenvironmental reconstruction," Palaeoworld, vol. 15, no. 3-4, pp. 217-222, 2006.

[29] Y. Wang, D. Dong, X. Li, J. Huang, S. Wang, and W. Wu, "Stratigraphic sequence and sedimentary characteristics of Lower Silurian Longmaxi Formation in Sichuan Basin and its peripheral areas," Natural Gas Industry B, vol. 2, no. 2-3, pp. 222-232, 2015.

[30] C. Mou, X. Wang, Q. Wang et al., "Relationship between sedimentary facies and shale gas geological conditions of the Lower Silurian Longmaxi Formation in southern Sichuan Basin and its adjacent areas," Journal of Palaeogeography, vol. 18 , no. 3, pp. 457-471, 2016.

[31] S. Li, Y. Zhou, and D. Sun, "Rock mechanic experiment study of evaluation on cap rock effectiveness," Petroleum Geology \& Experiment, vol. 35, no. 5, pp. 574-586, 2013.
[32] X. Guo, D. Hu, Y. Li, Z. Wei, X. Wei, and Z. Liu, "Geological factors controlling shale gas enrichment and high production in Fuling shale gas field," Petroleum Exploration and Development, vol. 44, no. 4, pp. 513-523, 2017.

[33] X. He, Y. Gao, X. Tang, P. Zhang, and G. He, “Analysis of major factors controlling the accumulation in normal pressure shale gas in the southeast of Chongqing," Natural Gas Geoscience, vol. 28, no. 4, pp. 654-664, 2017.

[34] Z. Wei, "Late fugitive emission of shale gas from Wufeng-Longmaxi Formation in Sichuan Basin and its periphery," Oil and Gas Geology, vol. 36, no. 4, pp. 659-665, 2015.

[35] H. Nie, S. Bao, B. Gao et al., "A study of shale gas preservation conditions for the Lower Paleozoic in Sichuan Basin and its periphery," Earth Science Frontiers, vol. 19, no. 3, pp. 280294, 2012.

[36] D. Hu, H. Zhang, K. Ni, and G. Yu, "Main controlling factors for gas preservation conditions of marine shales in southeastern margins of the Sichuan Basin," Natural Gas Industry, vol. 34, no. 6, pp. 17-23, 2014.

[37] J. Yu, Z. Yong, L. Cheng et al., "Index evaluation of shale gas reservation conditions of Longmaxi Formation in strong reconstruction zone," Journal of Yangtze University (Natural Science Edition), vol. 12, no. 35, pp. 1-7, 2015.

[38] G. Zhai, Y. Wang, S. Bao et al., "Major factors controlling the accumulation and high productivity of marine shale gas and prospect forecast in Southern China," Earth Science, vol. 42, no. 7, pp. 1057-1068, 2017.

[39] J. Zhang, Y. Li, H. Nie et al., "Geologic setting and drilling effect of the shale cored well Yuye-1, Penshui County of Chongqing," Natural Gas Industry, vol. 30, no. 12, pp. 114134, 2010.

[40] S. Li, Y. Wo, Y. Zhou, and W. Liu, "Controlling factors affect sealing capability of well-developed muddy cap rock," Acta Geologica Sinica, vol. 85, no. 10, pp. 1691-1697, 2011.

[41] T. Guo and P. Zeng, "The structural and preservation conditions for shale gas enrichment and high productivity in the Wufeng-Longmaxi Formation, Southeastern Sichuan Basin," Energy Exploration \& Exploitation, vol. 33, no. 3, pp. 259276, 2015.

[42] M. K. Hubbert, "Entrapment of petroleum under hydrodynamic conditions," AAPG Bulletin, vol. 37, no. 6, pp. 19542026, 1953.

[43] G. Liu and M. Sun, "Significance of excess differential pressure in highly efficient gas accumulation in over-pressured basins," Oil \& Gas Geology, vol. 28, no. 2, pp. 203-208, 2007.

[44] P. Wang, Z. Jiang, L. Chen et al., "Pore structure characterization for the Longmaxi and Niutitang shales in the Upper Yangtze platform, South China: evidence from focused ion beam-He ion microscopy, nano-computerized tomography and gas adsorption analysis," Marine and Petroleum Geology, vol. 77, pp. 1323-1337, 2016.

[45] P. Wang, Z. Jiang, W. Ji et al., "Heterogeneity of intergranular, intraparticle and organic pores in Longmaxi shale in Sichuan Basin, South China: evidence from SEM digital images and fractal and multifractal geometries," Marine and Petroleum Geology, vol. 72, pp. 122-138, 2016.

[46] Z. Gao and Q. Hu, "Wettability of Mississippian Barnett shale samples at different depths: investigations from directional spontaneous imbibition," AAPG Bulletin, vol. 100, no. 01, pp. 101-114, 2016. 
[47] Q. Hu, R. P. Ewing, and S. Dultz, "Low pore connectivity in natural rock," Journal of Contaminant Hydrology, vol. 133, pp. 76-83, 2012.

[48] R. Huang, Z. Jiang, Z. Gao et al., "Effect of composition and structural characteristics on spontaneous imbibition of shale reservoir," Petroleum Geology and Recovery Efficiency, vol. 24, no. 1, pp. 111-115, 2017.

[49] J. Gao, S. He, and J. Yi, "Discovery of high density methane inclusions in Jiaoshiba shale gas field and its significance," Oil and Gas Geology, vol. 36, no. 3, pp. 472-480, 2015.

[50] X. Wei, Z. Zhao, Q. Wang, Z. Liu, M. Zhou, and H. Zhang, "Comprehensive evaluation on geological conditions of the shale gas in Upper Ordovician Wufeng Formation-Lower Silurian Longmaxi Formation in Dingshan area, Qijiang, southeastern Sichuan," Geological Review, vol. 63, no. 1, pp. 153-164, 2017. 

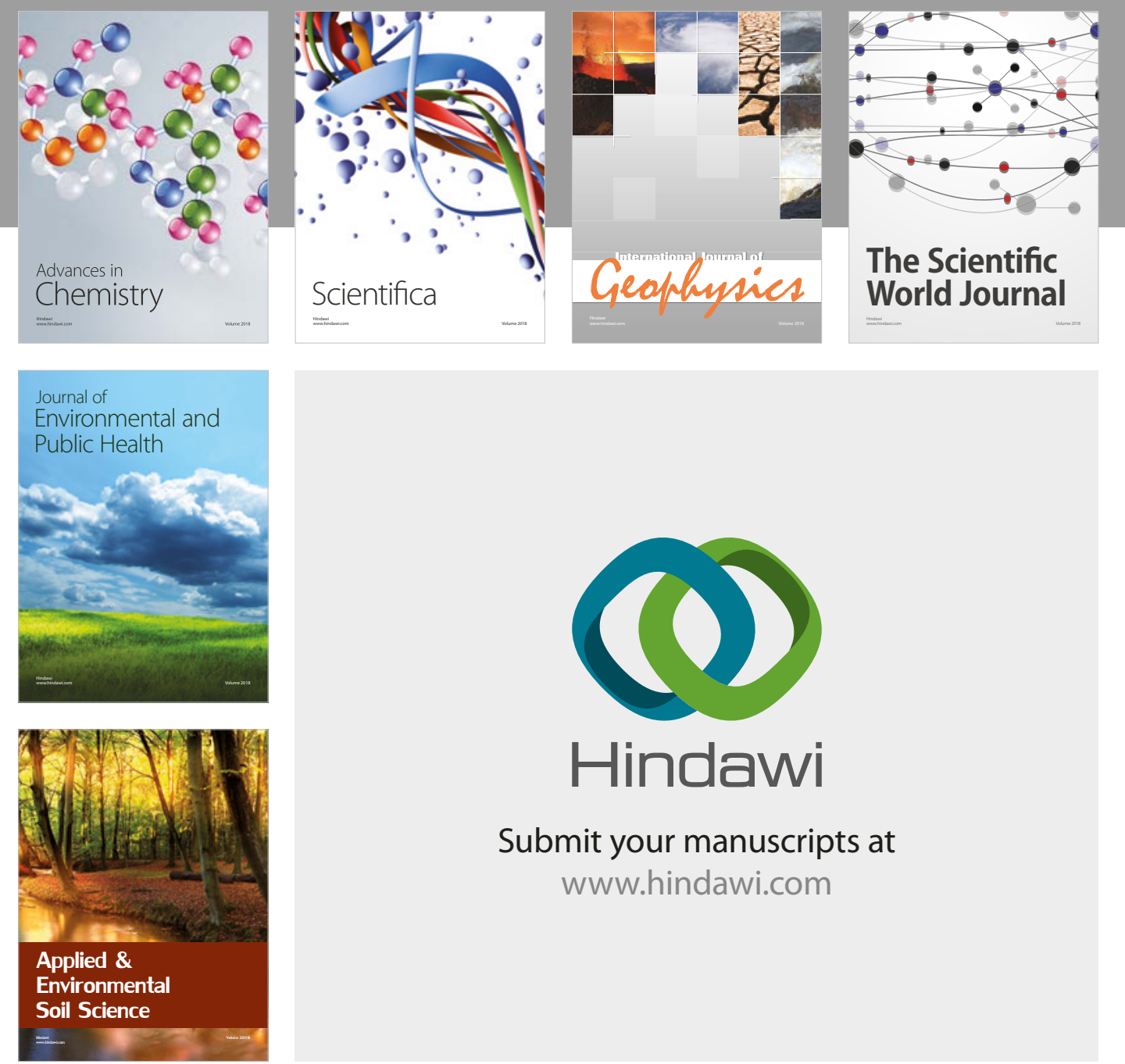

The Scientific

\section{World Journal}
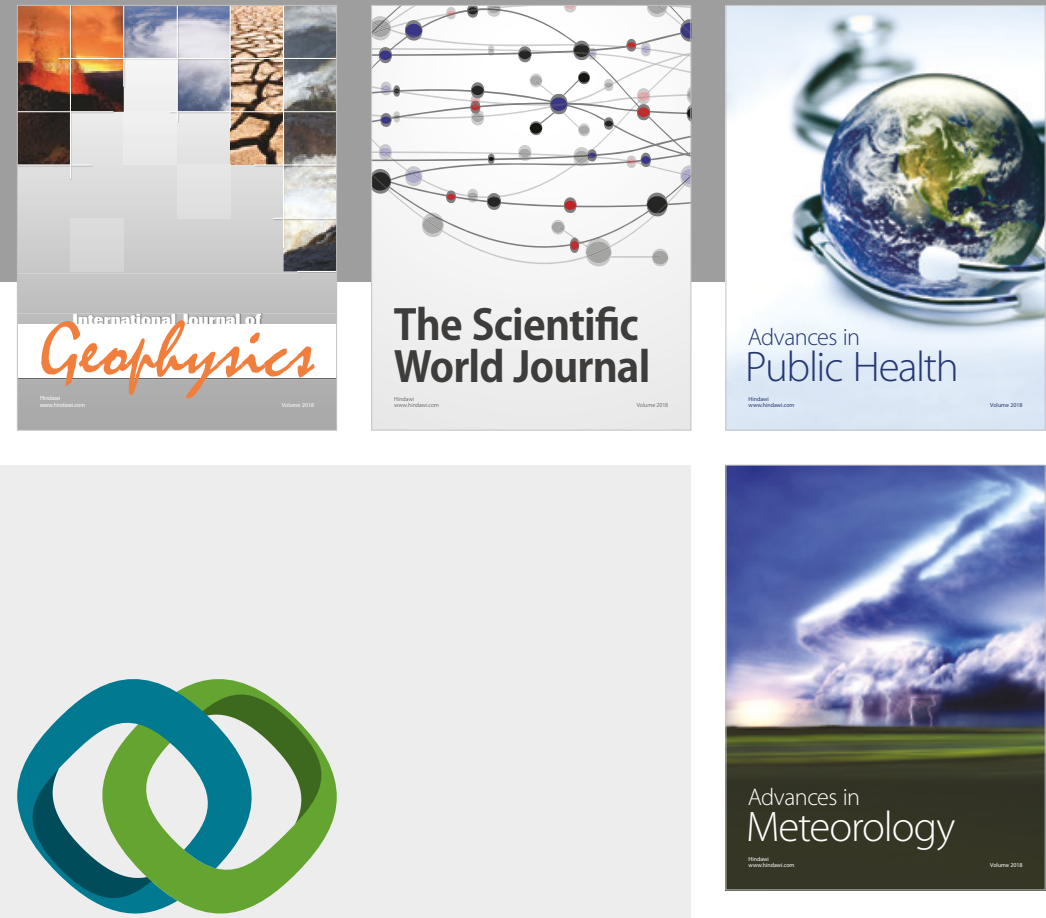

Advan

Public Health

\section{Hindawi}

Submit your manuscripts at

www.hindawi.com
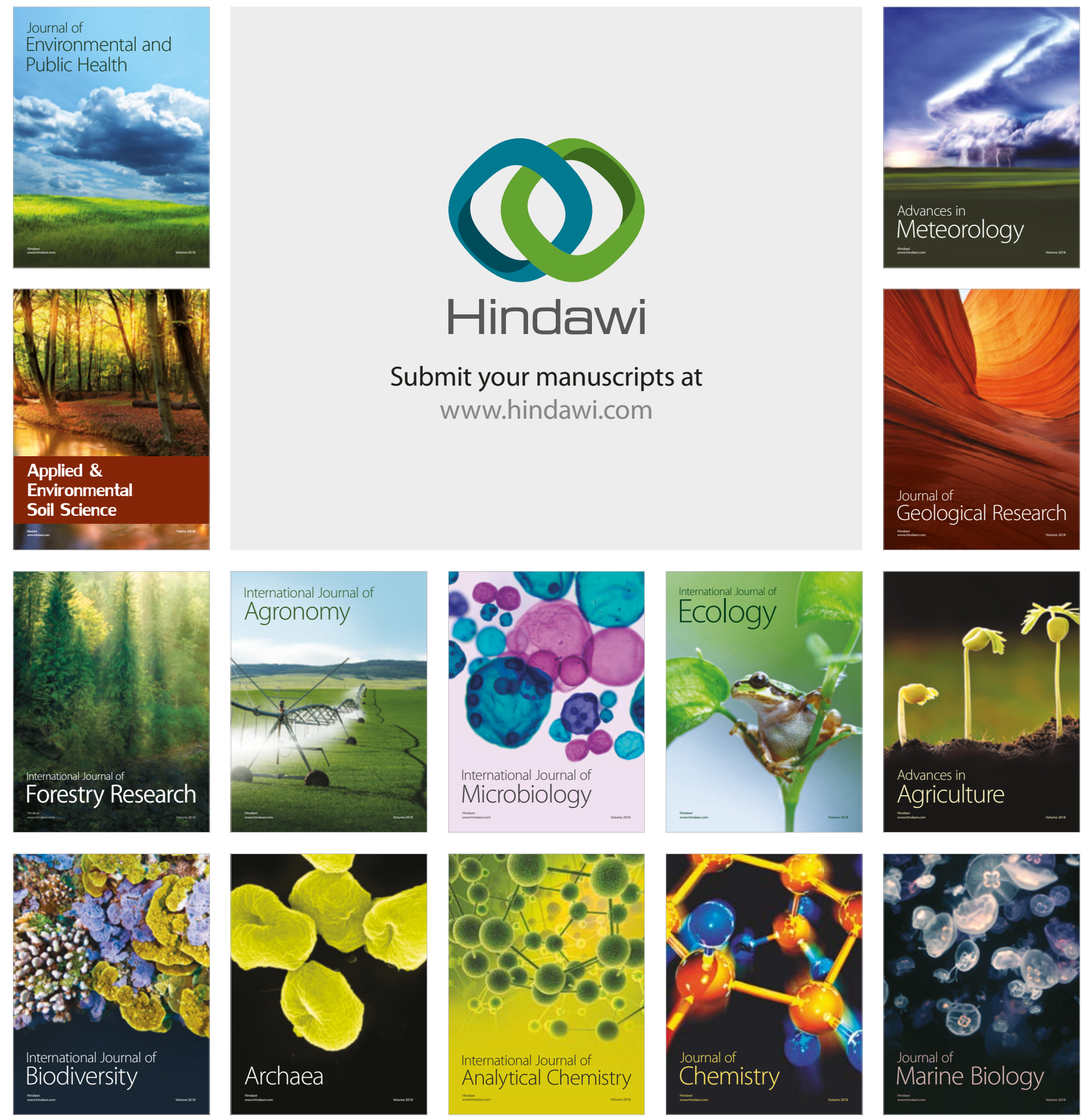